\title{
(Re)violências socialmente infligidas a meninos sexualmente abusados por mulheres
}

\author{
Double violence socially inflicted \\ on boys sexually abused by women \\ (Re)violencia socialmente infligida \\ a niños abusados sexualmente por mujeres
}

\author{
Camila Bahia Lessa ${ }^{*}$ \\ Andréa Soutto Mayor**
}

\section{Resumo}

No Brasil, foram reportados aproximadamente 776 casos de abuso sexual infantil (ASI) contra crianças e adolescentes do sexo masculino perpetrado por abusadoras femininas entre 2011 e 2017 (Brasil, 2018). Diversos estudos demonstram evidências de um processo particular na experiência do ASI de meninos, que entravam seu processo de revelação, tornando-o altamente subnotificada. Este artigo pretendeu capturar reações ao ASI de meninos quando cometido por mulheres, pela análise de conteúdo de 292 comentários em reportagens de domínio público que noticiaram casos reais dessa violência. Os resultados demonstraram preponderância do não reconhecimento das práticas sexuais entre mulheres adultas e meninos como abuso (81,5\%), contendo ataques depreciativos aos jovens, declarações de impossibilidade de vitimização destes, referências positivas à experiência, entre outras que banalizam a questão. Os múltiplos ataques virtuais registrados e a descaracterização dos casos como abusivos sugerem um processo de (re)vitimização socialmente infligida aos meninos sexualmente violentados, acarretando possíveis danos psicológicos secundários e reforçando estigmas e a subnotificação dessa violência.

Palavras-chave: violência sexual contra meninos, mulher ofensora sexual, abuso sexual infantil

* Universidade Federal Fluminense, RJ, Brasil. E-mail: cmllessa3@gmail.com

** Universidade Federal Fluminense, RJ, Brasil. E-mail: andreasouttomayor@id.uff.br 


\section{Abstract}

In Brazil, approximately 776 cases of child sexual abuse (CSA) against male children and adolescents perpetrated by female abusers were reported between 2011 and 2017 (Brazil, 2018). Several studies demonstrate evidence of a particular process in the boys' CSA experience, which impedes their disclosure process, making it highly underreported. This article aimed to capture reactions to boys' CSA when committed by women, by analyzing the content of 292 comments in public domain news that reported real cases of this violence. The results showed a preponderance of the lack of recognition of sexual practices among adult women and boys as abuse (81.5\%), containing derogatory attacks on boys, declarations of their impossibility of victimization, positive references to the experience, among other trivializing trends. The multiple virtual attacks and the mischaracterization of cases as abusive suggest a process of double victimization inflicted on sexually abused boys, causing possible secondary psychological damage, reinforcing stigmas and the underreporting of this violence.

Keywords: sexual violence against boys, female sexual offender, child sexual abuse

\section{Resumen}

En Brasil, fueron reportados aproximadamente 776 casos de abuso sexual infantil (ASI) contra niños y adolescentes del sexo masculino perpetrados por mujeres abusadoras entre 2011 y 2017 (Brasil, 2018). Varios estudios demuestran evidencias de un proceso particular en la experiencia de ASI de niños, que impide su proceso de divulgación, lo que la hace subnotificada. Este artículo tuvo como objetivo captar las reacciones al ASI de los niños cometida por mujeres, mediante el análisis del contenido de 292 comentarios en informes de dominio público que denunciaron casos reales de esa violencia. Los resultados mostraron una preponderancia del desconocimiento de las prácticas sexuales entre mujeres y niños como abuso (81,5\%), conteniendo agresiones despectivas a los jóvenes, declaraciones de imposibilidad de victimización, referencias positivas a la experiencia, entre otras tendencias banalizadoras. Los múltiples ataques virtuales registrados y la caracterización errónea de los casos como no abusivos sugieren un proceso de (re)victimización social infligido a los niños abusados sexualmente, provocando posibles daños psicológicos secundarios, reforzando los estigmas y el subregistro de esa violencia.

Palabras clave: violencia sexual contra niños; mujer ofensora sexual; abuso sexual infantil 
Para Azevedo e Guerra (1988), o abuso sexual infantil (ASI) é entendido como uma "relação hétero ou homossexual, entre um ou mais adultos e uma criança ou adolescente, tendo por finalidade estimular sexualmente esta criança ou adolescente ou utilizá-los para obter uma estimulação sexual sobre sua pessoa ou de outra pessoa" (p. 33). Apesar da multiplicidade de formas e arranjos de gênero em que o abuso pode manifestar-se, os estudos sobre o ASI, notadamente, têm enfoque no grupo de vítimas do sexo feminino - e homens como agressores sexuais -, enquanto há escassez da literatura na abordagem dessa violência com vítimas do sexo masculino (Finkelhor, 1990). A vitimização de meninos é menos expressiva em números, o que é parcialmente responsável por essa tendência. No entanto, estudos têm progressivamente questionado se os números de denúncias de ASI de meninos expressam a realidade de sua ocorrência, já que há evidências de que a frequência do ASI com a população masculina representa maior proporção do que a reconhecida até então pelas instituições responsáveis (Finkelhor, 1979).

Em Boletim Epidemiológico mais recente do Ministério da Saúde (Brasil, 2018), demonstra-se a incidência de casos de abuso sexual notificados no período de 2011 a 2017. Foram identificados que, entre os 58.037 casos de ASI contra crianças, 74,2\% das vítimas eram meninas, e 25,8\% eram meninos; e, entre os 83.068 casos contra adolescentes, 92,4\% das vítimas eram do sexo feminino, enquanto apenas 7,6\% eram do sexo masculino (Brasil, 2018). Esses dados refletem as denúncias que chegaram aos serviços de saúde, mas não há dados mais globais acerca da real incidência. Assim, entende-se que os números da violência sexual infantil refletem apenas uma parcela da realidade, principalmente ao considerar casos com vítimas do sexo masculino, que enfrentam subnotificação ainda mais acentuada (Carvalho, 2015). A baixa notificação e a falta de estudos acerca da temática simultaneamente reforçam e são reforçadas pela ausência de políticas públicas destinadas a esse grupo, em uma dinâmica que se retroalimenta.

Um nicho ainda mais específico do ASI de meninos, com um universo ainda mais inexplorado, trata-se das violações perpetradas por mulheres. Segundo Costa (2011), há escassez de dados sobre abusadoras e sobre a 
incidência real de casos em nível nacional e internacional. As informações existentes revelam que, das notificações do abuso sexual de crianças e adolescentes do sexo masculino, anteriormente apresentadas, respectivamente, $16,3 \%$ e $7,6 \%$ relataram agressoras do sexo feminino. Os meninos - sobretudo adolescentes - são mais propensos a serem vítimas de violação sexual por parte de mulheres em comparação com a vitimização do sexo oposto (Romano \& De Luca, 2001), ao passo que essas vítimas em particular tendem a ser mais silenciadas e a terem sua violência sexual invisibilizada.

Para diversos autores, o ASI de meninos tem potencial de acarretar sequelas físicas e psicológicas graves, características de vítimas dessa violência (Furniss, 1993; Watkins \& Bentovim, 1992; Zimmerman, 2012), sem haver atenuação condicionada ao sexo da violadora. A experiência de meninos sexualmente abusados é definida como uma violência perturbadora, produtora de ansiedade, causadora de sequelas no desenvolvimento, retraimento social, disfunções sexuais e perda de libido na vida adulta (Finkelhor, 1979). Há também a possibilidade de outros danos, incluindo déficits na memória, prejuízos no julgamento, na aprendizagem e no comportamento social, desajustamento psicossexual, fantasias parafílicas e reprodução da violência (Watkins \& Bentovim, 1992).

Além disso, meninos têm a violência sexual percebida como "menos séria" ou "não abusiva", enfrentam maiores dificuldades para revelar o abuso e recebem reações menos acolhedoras da família, dos serviços de proteção e da sociedade (Cashmore \& Shackel, 2014) - principalmente em casos com agressora feminina. Há rejeição da ideia de que mulheres podem ser abusadoras sexuais, incredulidade na concepção destas como dominadoras frente à figura masculina (ainda que infantil) e a desacreditação de que esta última pode ser vitimada (Davide, 2016; Finkelhor, 1979). Dessa forma, são identificadas crenças e mitos presentes na sociedade que estabelecem uma cultura de negação das ofensas sexuais cometidas por mulheres contra meninos, fator apontado por Tozdan, Briken e Dekker (2019) como influenciador do seu encobrimento e do consequente enfraquecimento da rede de proteção à infância. Dessa forma, o recorte do fenômeno em função do sexo da vítima e abusadora revela perspectivas sociais importantes. 
Diante das intempéries da vitimização sexual de crianças e adolescentes do sexo masculino, da baixa produção bibliográfica sobre o tema e da influência das representações sociais apontada por alguns autores, a presente pesquisa objetivou capturar as percepções e crenças de internautas em reportagens que retratavam casos reais de violência sexual cometida por mulheres contra meninos, visando a identificar a existência ou não de uma lógica de deslegitimação do ato como violência. Compreender essas percepções mostra-se relevante para embasar estudos, intervenções educacionais e terapêuticas que atendam às especificidades dessa violência em contexto com a realidade enfrentada pelas vítimas. Ademais, considerando o protagonismo do adoecimento psíquico envolvido na violência sexual (Gabel, 1997), é fundamental o papel da Psicologia no reconhecimento da complexidade do fenômeno em pauta, a fim de construir alicerces para um debate mais amplo acerca dos impactos na saúde mental desses meninos vítimas, considerando outros fatores adoecedores para além da violação sexual em si.

\section{MÉTODO}

Empregou-se um estudo de natureza básica com abordagem exploratória sequencial, integrando as perspectivas qualitativa e quantitativa. Por meio de busca em plataforma de compartilhamento de vídeos, obtiveram-se cinco reportagens de domínio público de telejornais de emissoras diversas, referentes a três casos de abuso sexual contra meninos perpetrado por mulheres, entre os anos de 2013 e 2019 (Tabela 1).

Tabela 1 - Conteúdo dos Vídeos Encontrados

\begin{tabular}{|c|c|}
\hline No & Descrição \\
\hline Video 1 & $\begin{array}{l}\text { Explanação breve sobre suposta violência sexual sofrida por um adolescente } \\
\text { de } 12 \text { anos, perpetrada por uma mulher. A reportagem informa a localidade e } \\
\text { o nome da autora do crime, que, segundo a Polícia Militar, confessa o crime } \\
\text { e relata a participação de mais dois adolescentes na filmagem do ato. Ela foi } \\
\text { indiciada por estupro de vulnerável. Apresenta a foto da suspeita com a face } \\
\text { desfocada e dois adolescentes de costas (Caso 1). }\end{array}$ \\
\hline
\end{tabular}




\begin{tabular}{|c|c|}
\hline $\mathrm{N}^{\circ}$ & Descrição \\
\hline Vídeo 2 & $\begin{array}{l}\text { Narrativa em programa ao vivo sobre o mesmo caso anterior (Caso 1), em que } \\
\text { a mesma foto e informações são apresentadas, acrescidas do dado de que a } \\
\text { gravação do crime viralizou nas redes sociais. }\end{array}$ \\
\hline Vídeo 3 & $\begin{array}{l}0 \text { apresentador inicia a reportagem apresentando a definição de estupro e } \\
\text { apontando o(a) violador(a) da integridade sexual afastado de uma lógica } \\
\text { hegemonicamente masculina. A reportagem, então, apresenta que um policial } \\
\text { autuou em flagrante uma mulher praticando sexo oral em adolescente de } \\
13 \text { anos em um carro, dando informações sobre a localidade e exibindo as } \\
\text { imagens de uma câmera de monitoramento. } 0 \text { soldado que fez a abordagem } \\
\text { é entrevistado e descreve sua ação. Segundo a reportagem, o adolescente } \\
\text { relatou que foi abordado na rua por uma motorista desconhecida e entrou no } \\
\text { veículo, que se encaminhou para uma rua deserta, onde o abuso ocorreu. } 0 \\
\text { apresentador, no final da reportagem, insinua que o adolescente não se trata de } \\
\text { uma vitima, tece acusações a este e ironiza o ocorrido (Caso 2). }\end{array}$ \\
\hline Video 4 & $\begin{array}{c}0 \text { mesmo caso do vídeo anterior (caso 2) é apresentado por reportagem de } \\
\text { outra emissora, exibindo os aspectos gerais do ocorrido, informações sobre a } \\
\text { perpetradora e uma entrevista com o soldado da Polícia Militar que realizou o } \\
\text { flagrante. Uma jornalista que conduz a reportagem expõe o explícito no Código } \\
\text { Penal Brasileiro sobre estupro de vulnerável. }\end{array}$ \\
\hline Video 5 & $\begin{array}{l}0 \text { apresentador explana sobre os comentários que estão sendo feitos nas } \\
\text { redes sociais da emissora sobre um caso de violência sexual sofrida por um } \\
\text { adolescente de } 13 \text { anos, supostamente cometido por sua professora em uma } \\
\text { escola particular. Critica a clara minimização do caso mediante as perspectivas } \\
\text { de gênero vigentes e reafirma se tratar de pedofilia }{ }^{1} \text { e ressalta a questão do } \\
\text { machismo. Segundo informado em entrevista com o delegado, a denúncia } \\
\text { parte da mãe, que observou mensagens com conteúdo sexual trocadas em } \\
\text { um aplicativo de mensagens. Quando questionado, o adolescente revela os } \\
\text { atos praticados e confirma a identidade da abusadora. Foram descobertos, no } \\
\text { celular da vitima, vídeos com conteúdo sexual. A reportagem apresenta fotos da } \\
\text { acusada sem qualquer preservação da identidade. }\end{array}$ \\
\hline
\end{tabular}

As reportagens tinham, em conjunto, um total de 760 comentários reativos até à data da coleta, dos quais foram desconsiderados comentários indiretos, sem conteúdo compreensível, ou com escrita ilegível. Essa triagem resultou em uma amostra de 292 comentários passíveis de categorização, e empregou-se a metodologia de análise de conteúdo de Bardin (1977/2011).

1 Enfatizamos alguns cuidados sobre a utilização desse termo, em vista da pressuposição atribuída ao "pedófilo" de este praticar relações abusivas com crianças ou adolescentes, correlação que não é absolutamente verdadeira. A pedofilia caracteriza uma preferência sexual, e não a prática abusiva em si. Portanto, ser portador(a) do transtorno não define se a pessoa é um(a) abusador(a) ou não, mas sua conduta. A questão será trabalhada no decorrer deste texto. 
Por meio da análise de conteúdo, além da compreensão do caráter comunicativo da mensagem, avaliam-se sentidos em segundo plano: os significantes e significados associados à ordem psicológica, sociológica, política e histórica contidos no discurso (Bardin, 1977/2011). Assim, considerando o caráter representacional da linguagem da análise do conteúdo, o estudo permite analisar construções que repousam sobre o tema investigado. A análise dos comentários obedeceu aos princípios metodológicos estabelecidos: (1) pré-análise; (2) exploração do material (codificação e categorização); (3) tratamento dos resultados, inferência e interpretação. A análise quantitativa estruturou-se em torno da análise descritiva da amostra, a fim de caracterizá-la e estabelecer correlações, por meio do software IBM-SPSS $®$.

\section{RESULTADOS E DISCUSSÃO}
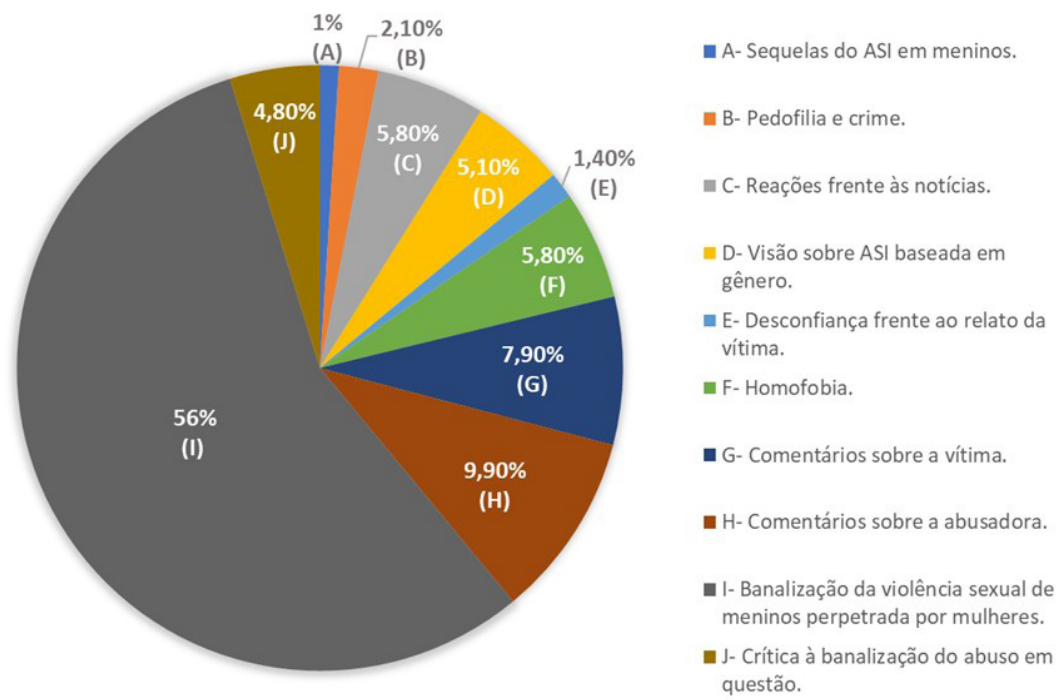

Figura 1. Categorias de conteúdo e incidências percentis da amostra de 292 comentários.

Conforme as ferramentas de análise estabelecidas, elencaram-se 10 categorias (Figura 1). À medida que a avaliação dos conteúdos dos comentários dos internautas foi aprofundada, surgiram crenças que perpassam a 
problemática a serem verificadas, conforme os objetivos. A apresentação e discussão individual sobre cada categoria foram feitas nos tópicos adiante, com transcrição na íntegra de seus comentários mais marcantes, incluindo os erros ortográficos e de digitação encontrados, para uma maior fidedignidade aos seus conteúdos.

\section{Sequelas do ASI em meninos}

I276: O menino, mas com certeza não será a mesmo pra sempre!!... Ele vai ficar com a coisa esquisita na cabeça...

I277: Tenho um sobrinho que foi usado pela Professora. Ele tinha 16 anos e ela engravidou. Falou para o marido que ele usou força com ela. Pra não ser morto tiramos ele da cidade. Hoje com 34 anos ainda tem pavor desta história e se fechou para novos relacionamentos. Todos acham graça, mas não imaginam o problema que isto pode causar.

A vitimização sexual na infância está associada a consequências múltiplas, com potencial de comprometimento físico, psicológico, cognitivo, afetivo e psicossexual (Teixeira-Filho, Rondini, Silva, \& Araújo, 2013; Romaro \& Capitão, 2007; Watkins \& Bentovim, 1992). Apesar do abuso deixar marcas em diversas esferas da vivência, o trauma psíquico é o aspecto central nesse tipo de violência (Gabel, 1997). Dessa forma, caracteriza-se como fator de risco para transtornos psicológicos graves, como depressão, ansiedade, fobias, transtornos alimentares, transtornos dissociativos de identidade, de personalidade e conduta, além de fator de risco para a dependência química (Pfeiffer \& Salvagni, 2005; Teixeira-Filho et.al, 2013). O explicitado está alinhado com o constatado por I276, em que se inferido o risco de transtornos mentais para as vítimas a longo prazo.

A problemática torna-se ainda mais específica em se tratando de violência sexual cometida contra meninos por mulheres. Pontua-se que o arranjo de sexo/gênero entre os atores não ameniza os impactos enfrentados pela vítima (Kristensen, 1996). Em estudo, com amostra de pessoas abusadas sexualmente por mulheres, a violência foi identificada como traumática, propiciadora de problemas envolvendo a automutilação, raiva, ideação suicida e dificuldade de relacionamento com mulheres (Denov, 
2004). Em consonância, Flores e Caminha (1994) ressaltam a diminuição da pró-sociabilidade em vítimas de ASI. Dessa forma, o "fechamento para relacionamentos" apontado por I277 está de acordo com o encontrado, implicando dificuldades no processo de desenvolvimento da vítima e, consequentemente, no envolvimento emocional e nas dinâmicas relacionais sadias.

Os comentários desta categoria $(n=3)$ abordam superficialmente os danos que podem ser causados às vítimas de ASI. Os internautas ilustram o encontrado que o ASI traz mudanças e impactos no desenvolvimento do menino vítima a curto e a longo prazos, condizentes com o explicitado na literatura. No entanto, apesar da relevância das sequelas dessa violência, foram realizados apenas três comentários com este sentido. Dessa forma, pode-se inferir um desconhecimento do público geral acerca dos impactos negativos da violência sexual perpetrada por mulheres contra meninos.

\section{Pedofilia e crime}

I255: O nome disso é pedofilia. Um crime.

I254: Isso não é pedofilia. É sim estupro de vulnerável, pois ele tem menos de 14 anos...

O transtorno pedofílico ou pedofilia é classificado como transtorno parafílico e caracterizado por impulsos ou preferências sexuais por crianças pré-púberes ou no início da puberdade, independentemente do sexo (American Psychiatric Association [APA], 2014). Os critérios diagnósticos estabelecidos no Manual Diagnóstico e Estatístico de Transtornos Mentais (DSM-5) incluem evidências do comportamento recorrentes persistindo por seis meses, que podem conter-se ao campo das fantasias sexualmente excitantes ou culminar em vias práticas de atividade de cunho sexual com crianças e adolescentes.

Ressalta-se que, por se tratar de um transtorno psiquiátrico que pode nunca ser de fato exteriorizado - mantendo-se no campo da fantasia -, a pedofilia não é equivalente ao ASI. Tendo em vista que apenas atos executórios podem ser conceituados como ilícitos, somente são considerados crimes ações que firam um bem jurídico (no caso, a dignidade ou liberdade 
sexual da criança). Logo, a pedofilia enquanto parafilia, não é sinônimo da prática sexualmente abusiva especificada na Lei - e seus portadores não são fatalmente agressores sexuais, como se associa na maioria dos comentários desta categoria.

Nesse aspecto, há muitos pedófilos pelo mundo que não cometem violência sexual e satisfazem-se sexualmente com fotos de revistas ou imagens despretensiosas de crianças, mas que geram neles intenso desejo sexual. Atuam na fantasia - e, muitas vezes, não têm coragem de pôr em ato seu real desejo. Não podemos dizer, portanto, que todo pedófilo seja um agressor sexual, e o inverso também não é verdadeiro (Brasil, 2004, p. 41).

Embora a pedofilia não se configure como manifestação material do abuso sexual, os termos são comumente utilizados como equivalentes pela mídia e pela sociedade em geral, tornando a pedofilia um termo vulgarizado (Lowenkron, 2007; Zúquete \& Noronha, 2012). De acordo com Landini (2003), em análise de reportagens referentes ao ASI publicadas no jornal Folha de S. Paulo, foi identificada a utilização da palavra "pedofilia" como sinônimo de abuso sexual, pornografia infantil e estupro (de menores) em diversos casos não correspondentes. Em levantamento, Lowenkron (2007) também sinalizou a ocorrência majoritária do termo em títulos de reportagens online que retratavam violência sexual infantil.

A palavra "pedofilia" usada como sinônimo da violência sexual infantil encontrada nos estudos demonstra o seu uso inadequado e a recorrência massificada do erro. O autor do comentário I254 articula corretamente esses conceitos ao expressar que os casos não são "crime" de pedofilia, mas de estupro de vulnerável. Os internautas restantes classificaram a autora como pedófila, associando o termo ao crime. Entende-se que, devido à popularização dos nomes técnicos dos transtornos e da utilização descuidada dos veículos de comunicação, há a ampliação dos equívocos na utilização do termo "pedofilia", construindo um conhecimento errôneo pelo senso comum. A despeito do uso inadequado do termo, os comentários desta categoria $(n=6)$ apresentam a condenação da violência sexual relatada e sua criminalização. 


\section{Reações frente às notícias}

I266: Provavelmente isso já acontecia as escondidas a muito tempo. Nada é oculto que não seja revelado. Que pague pelo crime!!! (Clamor por justiça) I272: Ela mora em minha cidade. Ela é uma mulher linda, casada e faz um absurdo desses. Só deus na causa! (Indignação)

I273: $C-H-O-C-A-D-A$ ! Como pode sentir atração por uma criança?!!!?! (Choque)

Conforme Lobo (2019), tratando-se da violência sexual infantil, a problemática "gera maior comoção e reprovabilidade social, sendo objeto de repúdio pela esmagadora parte da sociedade" (p. 12). Ante a visão contemporânea da infância como fase que carece de proteção integral e intimamente ligada ao cuidado, a violência exercida contra crianças e adolescentes - sobretudo de caráter sexual - fere diretamente valores relacionados à forma de enxergar esse ideário, implicando transgressão do dever protetivo do adulto e da sociedade em geral (Landini, 2005), ou seja, casos de ASI, comumente, geram repulsa da população, por ir de encontro aos valores socialmente construídos da infância como etapa a ser protegida.

A dinâmica de aversão encontrada na literatura manifestou-se pelos comentários que denunciavam a necessidade de condenação da agressora sexual, reconhecendo o ato relatado nos vídeos como ilícito $(n=7)$; os que expressavam revolta, repulsa e fúria $(n=6)$; e as reações que se resumiram a surpresa, espanto e até mesmo confusão $(n=4)$, sendo estes núcleos de sentido elaborados como as temáticas: "clamor por justiça”, "indignação" e "choque", respectivamente. Os comentários desta categoria $(n=17)$, portanto, estão em concordância com as reflexões encontradas na literatura acerca da violência sexual infantil e seu alto grau de desaprovação.

No entanto, apesar do encontrado na literatura, observou-se que os dados obtidos sob os parâmetros específicos de sexo/gênero da vítima/ abusadora não refletiram a dimensão esperada, visto que os comentários repreensivos não representaram incidência majoritária. Percebe-se que, proporcionalmente, poucos comentários foram despendidos nesses sentidos. Todavia, outras tendências foram observadas no estudo, que 
apontam para uma diferenciação da visão do abuso sob perspectivas específicas, evidenciadas nos próximos tópicos, o que pode esclarecer a baixa incidência de comentários reativos aversivos ao ato.

\section{Visão sobre ASI baseada em sexo/gênero}

I278: É muito mimimi. Um homem não faz sexo com uma mulher se ele não tiver ereção. Se o homem não quiser, simplesmente não acontece! O menino quis e brocou a professora gostosa. Qual problema nisso?

I287: Que danos causou ao jovem? Conheço diversos casos que não foram noticiados. Os garotos amam, ficam grandes e continuam felizes e de boa. Hipocrisia, cabeça de homem é diferente da cabeça feminina.

I288: Penso isso ainda e sempre vou pensar... Mulher é diferente de homem em vários aspectos! Eu queria ter tido essa sorte nessa idade! Kkkkkkkk.

Para Zimmermann (2012), a construção da mulher como vulnerável em contraposição ao homem a faz ser considerada não apenas como a provável vítima, como incapaz de impor sua vontade ou violência contra a figura masculina. Ainda segundo a autora, "esta condição pode resultar em dificuldades de concepção e assimilação da ideia do homem como vítima de um ato violento ou ocupando um lugar submetido numa relação violenta" (p. 18). Em outras palavras, existem mecanismos sociais que imputam à masculinidade padrões comportamentais baseados em um papel ativo associado à "virilidade e controle" (Carvalho, 2015; Finkelhor, 1979; Hayes \& Baker, 2014; Zimmermann, 2012). Em função dessa visão, a vitimização de mulheres e meninas é culturalmente mais aceita, e a masculina tende a ser invisibilizada (Pfeiffer \& Salvagni, 2005).

Em conformidade com a literatura exposta, nesta categoria $(n=$ 15), encontram-se comentários que invalidam a experiência traumática de meninos mediante ao abuso sexual por mulheres. O internauta I284 explicita: "só é abuso quando um homem maior faz sexo com uma mulher menor”, expressando a diferenciação na percepção de violência partindo da constatação do gênero dos envolvidos. Também foram identificadas insinuações de inexistência de repercussões negativas para os adolescentes retratados, exemplificada na declaração de I287. O internauta questiona os danos causados pela prática, sugerindo que esta não gera sequelas para 
meninos, declaração embasada em uma crença sexista: "cabeça de homem é diferente da cabeça feminina”. Assim, entende-se um compartilhamento da visão de que meninos não são negativamente afetados por essa violência em particular. Entretanto, “os meninos também são vitimados e apresentam sequelas não menos graves que as meninas" (Kristensen, 1996, p. 14).

Por intermédio de I278, demonstra-se mais um mito relacionado ao abuso sexual de meninos: a presunção da ereção da vítima como consentimento. Esse equívoco também foi tratado em outros comentários: "um homem (menino que seja) não endurece nunca o pau se ele não sentir prazer, totalmente o contrário de mulheres" (I282). A partir do transcrito, observa-se que, no caso de meninos, há a dificuldade de perceber o ato sexual como abusivo, principalmente uma vez que haja experimentação de prazer (Watkins \& Bentovim, 1992). Nos casos com agressoras mulheres, muitas vezes, é pressuposta a necessidade de que o menino esteja sexualmente excitado para que a prática seja realizada, desconsiderando que o abuso não necessariamente demanda a ereção deste, mas que esta pode ocorrer como resposta física involuntária aos estímulos em zonas erógenas, existindo a manifestação do prazer em função da ambivalência e dos elementos de gratificação secundária envolvidos no ASI (Furniss,1993).

Logo, é necessário pontuar que a resposta física e espontânea ou os sentimentos ambivalentes não legitimam o ato sexual de adultas com meninos e não o descaracteriza como abuso. No entanto, a lógica androcêntrica exposta nos comentários e na bibliografia, é identificada como influenciadora para a dificuldade na concepção da relação sexual entre mulheres e meninos como violação.

\section{Desconfiança frente ao relato da vítima}

I231: Não entendi. Quer dizer que o moleque de 12 anos, filmou o próprio estupro e ainda espalhou nas redes sociais? Que $m^{*}$, alguma coisa errada não está certa.

I233: Isso é mentira o mlk tava fazendo conversa fake pra colocar no YouTube. 
A visão contemporânea de crianças como indivíduos em fase especial de desenvolvimento, muitas vezes, leva à desvalorização da palavra destas em função de uma dicotomia preestabelecida entre adultos e crianças. À vista dessa crença cultural, em que se presume que "crianças mentem, enquanto adultos falam a verdade", ao abordar o tema do ASI existe uma maior dificuldade de acreditação na fala do menor molestado, uma vez que somos "impelidos a acreditar nos adultos" (Balbinotti, 2008, p. 8), e a percepcioná-los pelo viés do cuidado - principalmente, no caso de acusadas do sexo feminino. Segundo Azevedo (2001), em casos com adolescentes vítimas de ASI, a questão torna-se ainda mais complexa, e o descrédito é uma reação extremamente comum.

Tratando-se de meninos, há o agravante de que a sociedade tem mais dificuldades de observá-los como vítimas do ASI (Landor \& Eisenchlas, 2012). O comentário de I233 demonstra a criação de uma narrativa que, ao mesmo tempo, desmente a violência relatada pelo jovem e pressupõe outra cronologia de fatos, afastando-se da percepção de abuso. Em consonância, o comentário de I234: "Abuso sei, sonho de todo adolescente. Moleque vagabundo fala a verdade $\mathrm{f}^{*}$ " também levanta dúvidas sobre o testemunho da vítima, com o intuito de desmenti-lo. A presente categoria apresenta quatro comentários $(n=4)$.

Estudos nacionais e internacionais alegam uma maior dificuldade dos meninos no processo de revelação do ASI. O medo da descrença do relato de violência é um dos muitos fatores que impedem a quebra do silêncio de meninos sexualmente agredidos e frequentemente promove a negação ou retratação quando revelado (Baía, Veloso, Magalhães, \& Dell'Aglio, 2013; Balbinotti, 2008; Denov, 2003). O descrédito mediante o relato pode agir tanto previamente, desestimulando a divulgação do abuso pelo receio de não ser acreditado; quanto posterior à revelação, podendo ocorrer a concretização do medo inicial: a vivência da descrença no testemunho. As respostas de desacreditação do ASI, ou até mesmo a sua minimização agem como agravantes dos efeitos dessa violência, podendo provocar vitimizações secundárias (Denov, 2003). 


\section{Homofobia}

I242: É viado. Quando ficar maior vai ficar com medo de dizer pra mãe que e viado. E o pai puto com o filho por não deixar a professora abusa dele. I244: Muleke boca aberta tivesse ficado calado estava comendo ate hoje numa boa. Agora fica dando uma de inocente. Viadinho da mamãe.

I245: Quer moleque gayzão troxa fosse eu 방 $*$ $*$.

I248: Mais isso é uma bixona.

I249: Esse apresentador e uma bixona! A mãe do guri achar ruim até concordo! Mas estranho ficar dizendo isso ou aquilo...o rapazinho foi privilegiado...

O conceito de homofobia pode ser definido como "um conjunto de emoções negativas (aversão, desprezo, ódio ou medo) em relação às homossexualidades" (Borrillo, 2010, p. 7). Na estrutura social androcêntrica em que os papéis são determinados pelo sexo biológico, as características masculinas são valorizadas em detrimento dos valores atribuídos ao feminino. Isso cria uma dicotomia entre ambos os sexos, marcada pelo sexismo (Borrillo, 2010; Costa, 2011; Zimmermann, 2012). Segundo Borrillo (2010), a oposição manifesta-se na construção da masculinidade com rejeição das características ditas femininas, como a fragilidade e passividade. Dessa forma, em casos nos quais meninos se encontram no lugar de vítima e, portanto, “passíveis” a violência de terceiro, torna-se comum a consideração da homossexualidade, justamente por subverter o socialmente esperado do universo masculino.

Diversos autores corroboram que o medo da homossexualidade é uma experiência vivenciada por meninos vítimas de ASI e suas famílias. Almeida, Penso e Costa (2009, p. 47), apontam que “dentro do arcabouço de nossa cultura machista-patriarcal, recaem olhares e sentimentos aos meninos abusados que os impedem de retornar à condição de 'homens', restando-lhes o homossexualismo ${ }^{2}$ praticamente como um destino". Assim, a pressuposição de "ser menino vítima de ASI" ser correlato a "ser homossexual” implica barreiras socioculturais para a revelação.

2 O termo "homossexualismo" citado no texto de Almeida, Penso e Costa (2009) entrou em desuso a partir de sua retirada da $2^{\mathrm{a}}$ edição do Diagnostic and Statistical Manual of Mental Disorders (DSM-II) em 1973. Atualmente, o termo tem caráter pejorativo, visto que a homossexualidade não é considerada uma patologia ou síndrome, como o sufixo (“-ismo”) sugere. 
Em paralelo, presume-se que um menino não pode ser abusado por uma mulher em função do papel ativo no ato sexual, desconsiderando a relação de poder estabelecida no ASI (Davide, 2016) e a incapacidade de consentimento do menor. Uma leitura possível é a desacreditação de abusos de caráter sexual cometido por mulheres contra indivíduos do sexo masculino e a interrupção do sexo supostamente consentido como forma de confissão da homossexualidade, interpretação baseada na construção social masculina associada à virilidade exacerbada, em que não há espaço para negar oportunidades sexuais com mulheres, visto que a iniciativa sexual é socialmente aceita como prerrogativa masculina (Gonsiorek, 1994). Esse fato "dificulta que meninos falem sobre a experiência abusiva uma vez que pode levantar suspeitas sobre a sexualidade, tornando a revelação mais difícil em uma cultura homofóbica" (Zimmermann 2012, p. 34).

Os casos relatados, explicitados nesta categoria $(n=17)$, denunciaram a violência sexual confirmada pelos adolescentes, desencadeando o questionamento da orientação sexual como consequência. Como visto, há particularidades no universo masculino que podem tornar ainda mais difícil a revelação do abuso, entre elas as fantasias ligadas à homossexualidade. Ao passo que há a existência da estigmatização de meninos vítimas de ASI, a homofobia apresenta-se ao mesmo tempo como um fator impeditivo para a revelação de abuso, que, uma vez revelado, age como (re)violência direcionada a eles.

\section{Comentários sobre a vítima}

I194: Menino besta $:$ participa do bem bom depois deixa a mulher tá passando vexame com a polícia. (Críticas à vítima)

I195: Mlk burro. (Críticas a vítima)

I20o: Menino não é besta não, Br de atitude kkk. (Elogios à vítima)

I202: Mano esse mlk e um god.... (Elogios à vítima)

O receio dos julgamentos alheios é um dos aspectos experienciados por vítimas de ASI (Furniss, 1993; Kristensen, Oliveira \& Flores, 2000). As críticas encontradas direcionaram ofensas às vítimas proferidas em função de estas terem denunciado o abuso, assim interrompendo a continuidade 
do contato sexual com as agressoras. Seguindo essa mesma linha, os elogios constituintes dessa categoria atribuíram valor ao envolvimento sexual entre os pares, uma vez que as congratulações enfocaram o enaltecimento dos adolescentes por terem tido relações sexuais com mulheres prematuramente.

Entende-se que essas dinâmicas de elogio/críticas apontadas advêm de fatores psicológicos, sociais e culturais que contribuem para a não consideração de contato sexual de mulheres e meninos como abuso, à medida que o meio social não os percebe como vítimas (Landor \& Eisenchlas, 2012; Peluso \& Putnam, 1996 como citados em Baía et al., 2013). Essa dinâmica pôde ser observada em ambos os temas, pois, apesar de serem aparentemente opostos, ambos apelam em favor do contato sexual de meninos e mulheres, uma vez que os elogios parabenizam os meninos pelo envolvimento sexual, enquanto as críticas os condenam pela interrupção. Em suma, nesta categoria ( $n=23$ ), foi identificada uma inversão de valores, em que se atribuiu sentido negativo às revelações das vítimas e não ao abuso sexual em si, além da depreciação das narrativas e sofrimentos dos jovens sexualmente agredidos.

\section{Comentários sobre a abusadora}

I172: Uma velha doente. (Ofensas)

I165: Ela não merecia. (Defesa)

I186: Com uma professora dessa da um tesão pra estudar. (Sexualização) I167: Que professora linda hein! Os meninos piram. Linda mesma (Elogios)

Os comentários ofensivos foram constituídos de insultos de origem sexista, desmoralização, xingamentos, psicopatologização e desumanização da agressora. Estudos apresentaram resultados similares, em que as agressoras sexuais foram percepcionadas em algum grau como monstros, aberrações, párias, doentes mentais ou portadoras de psicopatologias (Davide, 2016; Hayes \& Baker, 2014). Os insultos proferidos expressam claramente o incômodo e desaprovação da relação dessas mulheres com meninos. Assim, esses comentários demonstram maior grau de percepção do abuso e do olhar sobre estas como agressoras sexuais de fato. 
O comentário único do tema defesa refere-se ao não merecimento da prisão da autora do abuso, tendência de desresponsabilização da ofensora sexual também identificada por outros autores em função do sexo/gênero desta (Davide, 2016; Hayes \& Baker, 2014). Em adição, a sexualização da abusadora foi observada em comentários com cunho sexual, apresentando referências eróticas. Enquanto isso, nos elogios, se enquadraram os comentários galanteadores que não continham conteúdo sexual explícito. Em análise, tanto a defesa quanto a sexualização e os elogios são compatíveis com a não percepção do abuso.

Nesta categoria $(n=29)$, foi possível inferir resultados mais equilibrados entre o reconhecimento e a desvalorização da violência sexual nos casos discutidos. No entanto, os comentários positivos (defesa, sexualização e elogios) em relação a agressoras $(n=15)$ ainda predominaram diante das ofensas ( $n=14)$, indicando algum grau de negligência do abuso, como já amplamente discutido.

\section{Banalização da violência sexual de meninos perpetrada por mulheres}

I28: Queria eu no lugar deste menino com uma coroa gostosa desta. (Desejo de estar no lugar da vítima)

I125: Eu não tive essa sorte de ser estuprado por uma mulher maravilhosa como essa. Garoto sortudo! Os pais deveriam agradecer à essa professora. (Insinuação do abuso ser positivo/sorte para a vítima)

I105: Se fosse meu filho ia me enxer de orgulho. (Incentivo ao abuso sexual de meninos por mulheres)

I14: Coroa deu com a xereca no mlk. (Comentário com conteúdo estritamente sexual)

I136: Queria a porra do link do vídeo RS. (Intenção/solicitação de assistir ao vídeo do abuso)

I161: E qual o crime nisso mlk com adulta meu isso pra min é uma benção. (Perspectiva de inexistência de estupro/abuso no caso)

I3: 13 Anos Já sabe muito Bem o Que faz Da Vida Sem Mimimi são Adolescentes formados Já. (Autonomia de menores para envolver-se em atos sexuais) 
I152: Comi minhas tias de 15 anos quando tinha 8 anos comi as amigas da minha irmã TBM de 15 anos e via minha tia se vestindo escondido debaixo da cama e alisei minha prima de 20 anos quando ela tava dormindo e hj sou um cara normal. (Naturalização da violência em questão)

A maioria dos comentários $(n=76)$ desta categoria evocou o desejo dos usuários em vivenciar as relações abusivas enfrentadas pelos adolescentes retratados, alegando o "Desejo de estar no lugar da vítima". Comentários alegando disponibilidade, solicitações de encontro com a abusadora, além do desejo do ocorrido ter acontecido na própria infância foram altamente incidentes, caracterizando a violência como "um sonho" almejado a ser vivido.

\section{BANALIZAÇÃO DA VIOLÊNCIASEXUAL DE MENINOS \\ PERPETRADA POR MULHERES: TEMASDA \\ CATEGORIA}

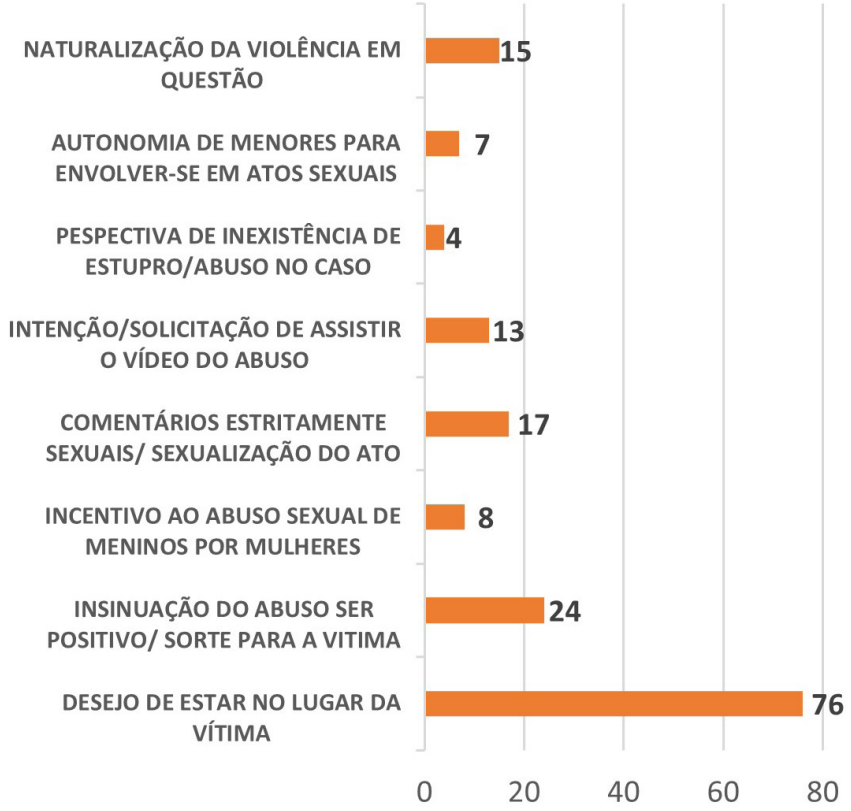

Figura 2. Gráfico com os temas da categoria "Banalização da violência sexual de meninos perpetrada por mulheres", com o número de comentários. 
Em consonância, na temática de insinuação de o abuso ser positivo ou sorte para a vítima $(n=24)$, diversos internautas reagiram referindo-se ao relatado como "sorte", "felicidade", ou expressões populares de favorecimento ao se referirem à vítima ("se deu bem”). Houve também parabenização aos envolvidos, sobretudo à abusadora, como, por exemplo, o explicitado por I131: "processa ela não tem que dar um trofel pra essa professora realizou o sonho da maioria dos meninos nessa idade”. Em suma, esta temática apresenta as alegações do público com a compreensão das relações sexuais entre mulheres e meninos como uma conquista ou benefício. Observa-se que a distorção na percepção acerca dessa violência específica permite a conivência com a prática.

Além da conformidade com a prática, surgiram comentários que assumiram a forma de incitação, formando o enunciado "Incentivo ao abuso sexual de meninos por mulheres" $(n=8)$. O encorajamento desse abuso se fez presente de forma direta e indireta. Para fins de ilustração, o internauta I102 emitiu: "Se fosse meu filho parabenizava e ainda dava um carro"; concordante, I105 afirma que ficaria orgulhoso de seu filho caso fosse abusado por uma mulher. Os conteúdos evocam o orgulho associado à iniciação sexual prematura de meninos e a estimulam de forma irresponsável.

Em meio às reações, foi necessária a criação de uma temática exclusiva para abordar os comentários com conteúdo estritamente sexual, formados pela erotização do ocorrido, com conteúdo inapropriado e comentários lascivos. A sexualização dessa violência também se fez presente nos comentários da temática "Intenção/solicitação de assistir ao vídeo do abuso" ( $n=13$ ), os quais expressam o desejo de verificar a existência ou assistir a filmagem dos abusos na íntegra.

Em adição, também foram encontrados comentários declarando a perspectiva de inexistência de abuso $(n=4)$, em que os internautas reagiram com declarações que afirmavam que os casos não eram uma violência, mas um ato consentido e prazeroso, fazendo afirmações categóricas sobre o assunto abordado não se tratar de abuso. Holmes, Offen e Waller (1997) 
elucidam que "a socialização masculina tende a incentivar os homens a definirem experiências sexuais como 'desejáveis', como um 'ritual de passagem', desde que não haja envolvimento homossexual” (p. 79).

Outra temática encontrada adveio de comentários afirmando que adolescentes têm autonomia de menores para envolver-se em atos sexuais ( $n=7$ ), os quais expressam que têm eles capacidade de consentimento, mesmo com pessoas com significativa diferença de idade. Essa concepção alinha-se com Azevedo (2001), ao relatar a existência do pressuposto social que adolescentes, por terem o desenvolvimento físico e psicológico mais avançado "evocam menos ingenuidade que as crianças" (p. 5), portanto, sendo mais facilmente considerados coniventes com a violência sexual.

Por fim, a temática "Naturalização da violência em questão" $(n=15)$, contém as reações em que os internautas normalizam a dinâmica abusiva abordada. Foram feitas revelações dos internautas acerca de abusos sofridos na infância, mas não eram vistas pelos relatores como violência. Ainda, declarações de identificação com a abusadora ou recordações do desejo sexual vivenciado na adolescência apresentaram-se como justificativas para a aceitação da relação entre meninos e mulheres. Todos os comentários desse tema exemplificam a normalização das relações sexuais precoces entre adultos e crianças, partindo das vivências próprias ou de outrem, trazendo o comportamento da violadora para as esferas do comum ou normal.

A negação sistemática do abuso sexual de meninos por mulheres vêm-se expressando nesses temas de múltiplas formas, com o teor comum de subestimação da violência. Uma vez constatada a atribuição de sentidos positivos, sexualmente satisfatórios e a consequente aceitação e incentivo do envolvimento sexual de mulheres adultas e menores incapazes, percebe-se uma dinâmica de banalização da problemática, descaracterizando o contexto abusivo e refletindo uma visão distorcida compartilhada acerca da problemática. 


\section{Crítica à banalização do abuso em questão}

I222: Por isso que o Brasil não evolui, estamos muitos anos atrasados. Quando um homem abusa de uma menina é pedofilia, quando uma mulher abusa de um menino, tem quem defenda. . .

I226: Se fosse menina todo mundo ia criticar, mas como e menino as pessoas acha norma. Ela tem que saber que é errado, ele é criança.

Uma vez que os internautas interagiram, tendo acesso às colocações um dos outros, a banalização majorante nos comentários foi identificada nesta categoria e constituiu-se alvo de críticas. O comentário de I222 censura a atribuição de normalidade à violência sexual de meninos em se tratando de mulheres abusadoras. Similarmente, I225 expressa: "Se fosse um professor abusando de uma aluna né? Agora se é um garoto abusado, aí é 'engraçado”'. A atribuição de humor e a desvalorização do ASI, encontrada em diversos dos comentários anteriormente abordados, foram reprovadas nesta categoria $(n=14)$, demonstrando maior sensibilidade quanto à vitimização de meninos.

As expectativas comportamentais impostas aos meninos afetam a forma que estes experienciam a violência sexual, sendo a invisibilização um dos perigos da banalização dessa violência. Por isso, o ASI de meninos "não pode ser negligenciado - como vem sendo -, pois estar biologicamente situado no grupo XY não o exime de experiências violentas que exigem políticas públicas, cuidado e afeto, assim como em casos de meninas" (Carvalho, 2015, p. 107).

\section{Análise descritiva da amostra e integração dos dados}

Em análise, identificamos que 81,8\% dos comentários foram realizados por internautas do sexo masculino. As internautas do sexo feminino representaram 10,6\% - e, ainda, 7,6\% dos perfis não identificaram o sexo (“I”, na Tabela 2). O predomínio de comentários realizados por mulheres foi identificado nas categorias/temas "Choque diante da notícia", "Pedofilia e crime" e "Ofensas à abusadora". Identificou-se a prevalência de comentários masculinos nas demais temáticas, como demonstra a Tabela 2. 


\section{Tabela 2 - Tabulação Cruzada entre as Variáveis \\ "Temas" e "Sexo" dos Internautas}

\begin{tabular}{|c|c|c|c|c|c|}
\hline \multirow{2}{*}{ Temas } & & \multicolumn{3}{|c|}{ Sexo } & \multirow{2}{*}{ Total } \\
\hline & & $\mathrm{F}$ & 1 & $\mathrm{M}$ & \\
\hline \multirow{2}{*}{$\begin{array}{l}\text { Autonomia de menores para } \\
\text { envolver-se em atos sexuais }\end{array}$} & \multirow{2}{*}{$\begin{array}{l}\text { Contagem \% } \\
\text { em TEMAS }\end{array}$} & 0 & 1 & 6 & 7 \\
\hline & & $0,0 \%$ & $14,3 \%$ & $85,7 \%$ & $100 \%$ \\
\hline \multirow{2}{*}{ Choque (diante da notícia) } & \multirow{2}{*}{$\begin{array}{l}\text { Contagem \% } \\
\text { em TEMAS }\end{array}$} & 4 & 0 & 0 & 4 \\
\hline & & $100 \%$ & $0,0 \%$ & $0,0 \%$ & $100 \%$ \\
\hline \multirow{2}{*}{ Clamor por justiça } & \multirow{2}{*}{$\begin{array}{l}\text { Contagem \% } \\
\text { em TEMAS }\end{array}$} & 1 & 2 & 4 & 7 \\
\hline & & $14,3 \%$ & $28,6 \%$ & $57,1 \%$ & $100 \%$ \\
\hline \multirow{2}{*}{$\begin{array}{l}\text { Comentários estritamente sexuais/ } \\
\text { sexualização do ato }\end{array}$} & \multirow{2}{*}{$\begin{array}{l}\text { Contagem \% } \\
\text { em TEMAS }\end{array}$} & 0 & 2 & 15 & 17 \\
\hline & & $0,0 \%$ & $11,8 \%$ & $88,2 \%$ & $100 \%$ \\
\hline \multirow{2}{*}{$\begin{array}{l}\text { Crítica à banalização do abuso } \\
\text { perpetrado por mulheres contra } \\
\text { meninos }\end{array}$} & \multirow{2}{*}{$\begin{array}{l}\text { Contagem \% } \\
\text { em TEMAS }\end{array}$} & 1 & 1 & 12 & 14 \\
\hline & & $7,1 \%$ & $7,1 \%$ & $85,7 \%$ & $100 \%$ \\
\hline \multirow{2}{*}{ Crítica à vítima } & \multirow{2}{*}{$\begin{array}{l}\text { Contagem \% } \\
\text { em TEMAS }\end{array}$} & 0 & 1 & 5 & 6 \\
\hline & & $0,0 \%$ & $16,7 \%$ & $83,3 \%$ & $100 \%$ \\
\hline \multirow{2}{*}{ Defesa da abusadora } & \multirow{2}{*}{$\begin{array}{l}\text { Contagem \% } \\
\text { em TEMAS }\end{array}$} & 0 & 0 & 1 & 1 \\
\hline & & $0,0 \%$ & $0,0 \%$ & $100 \%$ & $100 \%$ \\
\hline \multirow{2}{*}{ Desconfiança do relato da vítima } & \multirow{2}{*}{$\begin{array}{l}\text { Contagem \% } \\
\text { em TEMAS }\end{array}$} & 1 & 0 & 3 & 4 \\
\hline & & $25,0 \%$ & $0,0 \%$ & $75,0 \%$ & $100 \%$ \\
\hline \multirow{2}{*}{ Desejo de estar no lugar da vítima } & \multirow{2}{*}{$\begin{array}{l}\text { Contagem \% } \\
\text { em TEMAS }\end{array}$} & 0 & 1 & 75 & 76 \\
\hline & & $0,0 \%$ & $1,3 \%$ & $98,7 \%$ & $100 \%$ \\
\hline \multirow{2}{*}{ Elogio à abusadora } & \multirow{2}{*}{$\begin{array}{l}\text { Contagem \% } \\
\text { em TEMAS }\end{array}$} & 0 & 0 & 5 & 5 \\
\hline & & $0,0 \%$ & $0,0 \%$ & $100,0 \%$ & $100 \%$ \\
\hline \multirow{2}{*}{ Elogio à vítima } & \multirow{2}{*}{$\begin{array}{l}\text { Contagem \% } \\
\text { em TEMAS }\end{array}$} & 0 & 0 & 17 & 17 \\
\hline & & $0,0 \%$ & $0,0 \%$ & $100 \%$ & $100 \%$ \\
\hline Homofobia & Contagem $\%$ & 2 & 4 & 11 & 17 \\
\hline & em TEMAS & $11,8 \%$ & $23,5 \%$ & $64,7 \%$ & $100 \%$ \\
\hline Incentivo ao abuso sexual de meninos & Contagem \% & 0 & 0 & 8 & 8 \\
\hline por mulheres & em TEMAS & $0,0 \%$ & $0,0 \%$ & $100 \%$ & $100 \%$ \\
\hline Indianacão (ante a violência) & Contagem \% & 2 & 1 & 3 & 6 \\
\hline & em TEMAS & $33,3 \%$ & $16,7 \%$ & $50,0 \%$ & $100 \%$ \\
\hline Insinuação do abuso ser positivo/sorte & Contagem $\%$ & 2 & 3 & 19 & 24 \\
\hline para a vítima & em TEMAS & $8,3 \%$ & $12,5 \%$ & $79,2 \%$ & $100 \%$ \\
\hline Intenção/solicitação de assistir ao & Contagem $\%$ & 0 & 0 & 13 & 13 \\
\hline vídeo do abuso & em TEMAS & $0,0 \%$ & $0,0 \%$ & $100 \%$ & $100 \%$ \\
\hline Naturalizacão da violência em questão & Contagem \% & 2 & 0 & 13 & 15 \\
\hline & em TEMAS & $13,3 \%$ & $0,0 \%$ & $86,7 \%$ & $100 \%$ \\
\hline Ofensas à a busadora & Contagem $\%$ & 7 & 2 & 5 & 14 \\
\hline 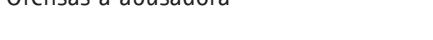 & em TEMAS & $50,0 \%$ & $14,3 \%$ & $35,7 \%$ & $100 \%$ \\
\hline Pedofilia e crime & Contagem \% & 4 & 2 & 0 & 6 \\
\hline Pedotilla e crime & em TEMAS & $66,7 \%$ & $33,3 \%$ & $0,0 \%$ & $100 \%$ \\
\hline Perspectiva de inexistência de & Contagem \% & 1 & 0 & 3 & 4 \\
\hline estupro/abuso no caso & em TEMAS & $25,0 \%$ & $0,0 \%$ & $75,0 \%$ & $100 \%$ \\
\hline
\end{tabular}




\begin{tabular}{llcccc}
\hline \multirow{2}{*}{ Temas } & & \multicolumn{3}{c}{ Sexo } & \multirow{2}{*}{ Total } \\
\cline { 3 - 4 } & & $\mathrm{F}$ & $\mathrm{I}$ & $\mathrm{M}$ & \\
\hline \multirow{2}{*}{ Sequelas do abuso sexual de meninos } & Contagem $\%$ & 1 & 1 & 1 & 3 \\
& em TEMAS & $33,3 \%$ & $33,3 \%$ & $33,3 \%$ & $100 \%$ \\
Sexualização da abusadora & Contagem $\%$ & 2 & 0 & 7 & 9 \\
Visão sobre ASI baseada em sexo/ & em TEMAS & $22,2 \%$ & $0,0 \%$ & $77,8 \%$ & $100 \%$ \\
gênero & Contagem $\%$ & 1 & 1 & 13 & 15 \\
& em TEMAS & $6,7 \%$ & $6,7 \%$ & $86,7 \%$ & $100 \%$ \\
Total: & Contagem $\%$ & 31 & 22 & 239 & 292 \\
& em TEMAS & $10,6 \%$ & $7,5 \%$ & $81,8 \%$ & $100 \%$ \\
\hline
\end{tabular}

Buscando esclarecimentos sobre o questionamento se o perfil dos internautas age como um influenciador ou não dos resultados, realizou-se a tabulação cruzada entre as variáveis "sexo" e "temas", encontrando correlação altamente significativa $(p \leq 0,01)$. Ante aos dados integrados, surgiram evidências de que os internautas do sexo masculino deste estudo mostraram-se menos propensos a validar as relações entre adultas e meninos como abusivas (Figura 2). Essa reflexão foi feita em função da maior associação destes com as temáticas que sinalizaram, na análise qualitativa, o não reconhecimento da violência em pauta. De modo geral, o público feminino demonstrou maior reconhecimento do ASI (Figura 3).

\section{RELAÇÃO DO SEXO DOS INTERNAUTAS COM O RECONHECIMENTO OU NÃO ACERCA DO ASI (BASEADO NAS TEMÁTICAS)}

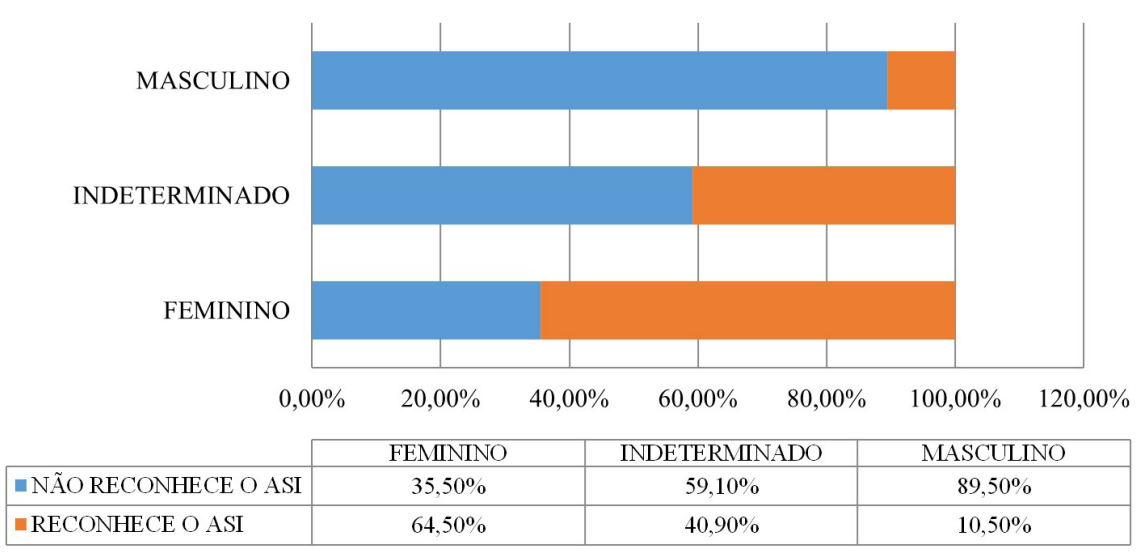

Figura 3. Gráfico de barras com correlação entre o sexo dos internautas e o reconhecimento ou não de ASI nos comentários. 
Apesar das correlações apontadas entre os sentidos dos comentários e o sexo dos participantes, outros fatores relevantes para a realização de conclusões mais generalizáveis não foram contemplados. Mediante a forma de coleta dos dados elaborada para uma investigação qualitativa, não foi possível fazer previamente a formulação de uma amostra mais representativa, o que permitiria dados com maior capacidade de generalização. Portanto, este tópico trata-se da descrição do perfil dos internautas responsáveis pelos comentários - através das informações as quais se teve acesso -, objetivando a validação interna da pesquisa.

\section{CONSIDERAÇÕES FINAIS}

Ao falar sobre violência sexual, é quase automática a representação da mulher ou menina como a abusada e de um homem como o abusador, fato compreensível mediante as representações de gênero vigentes e a maior identificação de crimes nesses parâmetros. Entretanto, o ASI de meninos é uma realidade subnotificada que necessita de maior visibilização (Brasil, 2018). A despeito das mudanças político-legais e sociais, o progresso nas definições -cada vez mais completas - do que é o ASI encontra percalços no reconhecimento da vitimização sexual de meninos de forma concreta. Em casos que contam com perpetradoras do sexo feminino, essa dificuldade é redobrada, por tratar-se de uma dupla subversão de concepções acerca da violência sexual: a imagem preconcebida da mulher e a do menino enquanto figura masculina.

Os resultados encontrados demonstraram o predomínio de opiniões e crenças dos internautas em temáticas associadas ao não reconhecimento da violência em pauta. A ocorrência de comentários relacionados ao reconhecimento acerca do ASI de meninos perpetrados por mulheres representou apenas $18,5 \%$ dos comentários totais e foi constituído pelas categorias/ temas: Sequelas sobre o ASI (1\%); Pedofilia e crime (2,1\%); Reações frente às notícias (5,8\%); Ofensas à abusadora (4,8\%); e Crítica à banalização do abuso em questão $(4,8 \%)$. Os comentários abordaram essa violência de forma crítica, apresentando reações condenatórias a esta e à abusadora, reconhecendo sua criminalização e os possíveis danos à vítima. Nesta 
amostra, foi encontrada correlação entre mulheres e uma maior percepção dos casos noticiados como sexualmente abusivos, o que, mediante as limitações da pesquisa, não pode ser generalizado.

Em contrapartida, a maioria dos comentários da amostra (81,5\%) indicou a minimização ou desqualificação das práticas sexuais reportadas entre mulheres e adolescentes como abusivas, englobando as categorias/ temas: Visão sobre ASI baseada em sexo/gênero (5,1\%); Desconfiança frente ao relato da vítima (1,4\%); Homofobia (5,8\%); Comentários sobre a vítima (7,9\%); Defesa, sexualização e elogios à abusadora (5,1\%); e todos os temas da categoria Banalização da violência sexual de meninos perpetrada por mulheres $(56,2 \%)$. Nesta pesquisa, constatou-se maior dificuldade de homens para a identificação de meninos como vítimas e mulheres como abusadoras, o que, novamente, não pode ser generalizado pela irregular distribuição de sexo da amostra em função da maior interação destes com as reportagens e do desconhecimento do sexo de parte dos internautas, sendo necessárias outras pesquisas para a afirmação de uma correlação entre o sexo dos participantes e a minimização desta violência.

Constatou-se, nos comentários das temáticas de não reconhecimento da violência sexual de meninos perpetrados por mulheres, a interpretação compartilhada desse abuso como positivo, a presunção da impossibilidade de meninos serem vítimas de ASI (em função do sexo/gênero, da idade, da aparência da abusadora) e a romantização e sexualização dos supostos abusos retratados, apresentando tendência de invalidar a experiência como traumática. Ademais, os adolescentes sofreram ataques homofóbicos, comentários de desconfiança, gozação, críticas e xingamentos por terem revelado o abuso. Esses resultados demonstram a concretização dos medos encontrados na literatura, apontados como desmotivadores do processo de revelação de violências sexuais de meninos, não se tratando, portanto, de um receio irreal, mas de barreiras socioculturais fortemente alicerçadas, que agem como uma (re)violência socialmente infligida após a revelação do abuso.

Dessa forma, a descaracterização da violência sexual de meninos perpetrada por mulheres mitiga a real dimensão da problemática, escusam as abusadoras dos seus atos criminosos e as vítimas de um processo de 
revelação do abuso digno. É fundamental, portanto, o reconhecimento das especificidades desse fenômeno tão pouco estudado, uma vez que os danos causados à integridade física e psicológica de meninos sexualmente agredidos por mulheres não advêm estritamente do ato de violação, mas também das reações sociais negativas promotoras de vitimizações secundárias.

\section{REFERÊNCIAS}

Almeida, T. M. C., Penso, M. A. P., \& Costa, L. F. (2009). Abuso sexual infantil masculino: O gênero configura o sofrimento e o destino? Estilos da Clínica, 14(26), 46-67. Recuperado de http://pepsic.bvsalud.org/ scielo.php?script=sci_arttext\&pid=S1415-71282009000100004

American Psychiatric Association. (2014). Manual diagnóstico e estatístico de transtornos mentais (5. ed.). São Paulo: Artmed.

Azevedo, E. C. D. (2001). Atendimento psicanalítico a crianças e adolescentes vítimas de abuso sexual. Psicologia: Ciência e Profissão, 21(4), 66-77. https://doi.org/10.1590/S1414-98932001000400008

Azevedo, M. A., \& Guerra, V. N. A. (1988). Pele de asno não é só história: Um estudo sobre a vitimização sexual de crianças e adolescentes em família. São Paulo: Roca.

Baía, P. A. D., Veloso, M. M. X., Magalhães, C. M. C., \& Dell'Aglio, D. D. (2013). Caracterização da revelação do abuso sexual de crianças e adolescentes: Negação, retratação e fatores associados. Temas em Psicologia, 21(1), 193-202. http://dx.doi.org/10.9788/TP2013.1-14

Balbinotti, C. (2008). A violência sexual infantil intrafamiliar: A revitimização da criança e do adolescente vítimas de abuso. Direito \& Justiça, 35(1), 5-21. Recuperado de https://revistaseletronicas.pucrs.br/ojs/index. $\mathrm{php} /$ fadir/article/view/8207

Bardin, L (2011). Análise de conteúdo. Lisboa: Edições 70. (Trabalho original publicado em 1977)

Borrillo, D. (2010). História e crítica de um preconceito. Belo Horizonte: Autêntica. 
Brasil. Ministério da Educação. (2004). Guia escolar: Métodos da identificação de sinais de abuso e exploração sexual de crianças e adolescentes. Brasília: Secretaria Especial dos Direitos Humanos, Ministério da Educação.

Brasil. Ministério da Saúde. (2018). Análise epidemiológica da violência sexual contra crianças e adolescentes no Brasil, 2011 a 2017. Boletim Epidemiológico, 49(27), 1-17. Recuperado de https://antigo.saude. gov.br/images/pdf/2018/junho/25/2018-024.pdf

Carvalho, F. A. (2015). Homem não chora: O abuso sexual contra meninos. (Tese de doutorado). Pontifícia Universidade Católica de São Paulo, São Paulo, Brasil.

Cashmore, J., \& Shackel, R. (2014). Gender differences in the context and consequences of child sexual abuse. Current Issues in Criminal Justice, 26(1), 75-104. https://doi.org/10.1080/10345329.2014.12 036008

Costa, C. F. P. D. (2011). Abuso sexual cometido por mulheres: Um estudo de caso (Dissertação de mestrado). Universidade Fernando Pessoa, Porto, Portugal.

Davide, D. A. S. (2016). Representações sociais do abuso sexual de crianças perpetrado por mulheres (Dissertação de mestrado). Universidade do Porto, Porto, Portugal.

Denov, M. S. (2003). The myth of innocence: Sexual scripts and the recognition of child sexual abuse by female perpetrators. The Journal of Sex Research, 4O(3), 303-314. https://doi. org/10.1080/00224490309552195

Denov, M. S. (2004). Long-term effects of child sexual abuse by female perpetrators: A qualitative study of male and female victims. Journal of Interpersonal Violence, 19(10), 1137-1156. https://doi. org/10.1177/0886260504269093

Finkelhor, D. (1979). What's wrong with sex between adults and children. American Journal of Orthopsychiatry, 49(4), 692-697. https://doi. org/10.1111/j.1939-0025.1979.tbo2654.x 
Finkelhor, D. (1990). Early and long-term effects of child sexual abuse: An update. Professional Psychology: Research and Practice, 21(5), 325-330. https://doi.org/10.1037/0735-7028.21.5.325

Flores, R. Z., \& Caminha, R. M. (1994). Violência sexual contra crianças e adolescentes: Algumas sugestões para facilitar o diagnóstico correto. Revista de Psiquiatria do Rio Grande do Sul, 16(2), 158-167.

Furniss, T. (1993). Abuso sexual da criança: Uma abordagem multidisciplinar, manejo, terapia e intervenção legal. Porto Alegre: Artes Médicas.

Gabel, M. (1997). Crianças vítimas de abuso sexual. São Paulo: Grupo Editorial Summus.

Gonsiorek, J. C. (1994). Male sexual abuse: A trilogy of intervention strategies. Thousand Oaks: Sage.

Hayes, S., \& Baker, B. (2014). Female sex offenders and pariah femininities: Rewriting the sexual scripts. Journal of Criminology, 1(2014), 1-8. https://doi.org/10.1155/2014/414525

Holmes, G. R., Offen, L., \& Waller, G. See no evil, hear no evil, speak no evil: Why do relatively few male victims of childhood sexual abuse receive help for abuse-related issues in adulthood? Clinical Psychology Review, 17(1), 69-88. https://doi.org/10.1016/ so272-7358(96)0oo47-5

Kristensen, C. H. (1996). Abuso sexual em meninos (Dissertação de mestrado). Universidade Federal do Rio Grande do Sul, Porto Alegre, Brasil.

Kristensen, C. H., Oliveira, M. S. \& Flores, R. Z. (2000). Violência contra crianças e adolescentes na Grande Porto Alegre. Parte B: Pode piorar? In Associação de Apoio à Criança e ao Adolescente (Org.), Violência doméstica (pp. 104-117). Brasília: UNICEF.

Landini, T. S. (2003). Pedófilo, quem és? A pedofilia na mídia impressa. Cadernos de Saúde Pública, 19, S273-S282. https://doi.org/10.1590/ So102-311X2003000800009

Landini, T. S. (2005). Horror, honra e direitos: Violência sexual contra crianças e adolescentes no século XX (Tese de doutorado). Universidade de São Paulo, São Paulo, Brasil. 
Landor, R. V., \& Eisenchlas, S. A. (2012). “Coming clean” on duty of care: Australian print media's representation of male versus female sex offenders in institutional contexts. Sexuality \& Culture, 16(4), 486-502. https://doi.org/10.1007/s12119-012-9134-5

Lobo, C. F. F.S (2019). Abuso sexual infantil: Consequências psicossociais do crime e a revitimização provocada pela inquirição à vítima. Revista Jurídica do Ministério Público de Rondônia, 3, 11-29. Recuperado de https://esmpronet.mpro.mp.br/revistas/3/Artigo\%2094.pdf

Lowenkron, L. (2007). (Menor) idade e consentimento sexual em uma decisão do STF. Revista de Antropologia, 5o(2), 713-745. https:// doi.org/10.1590/So034-77012007000200007

Pfeiffer, L., \& Salvagni, E. P. (2005) Visão atual do abuso sexual na infância e adolescência. Jornal de Pediatria, 81(5), 197-204. https://doi. org/10.1590/Soo21-75572005000700010

Romano, E., \& De Luca, R. V. (2001). Male sexual abuse: A review of effects, abuse characteristics, and links with later psychological functioning. Aggression and Violent Behavior, 6(1), 55-78. https:// doi.org/10.1016/S1359-1789(99)ooo11-7

Romaro, R. A., \& Capitão, C. G. (2007). As faces da violência: Aproximações, pesquisas e reflexões. São Paulo: Vetor Editora.

Teixeira-Filho, F. S., Rondini, C. A., Silva, J. M., \& Araújo, M. V. (2013). Tipos e consequências da violência sexual sofrida por estudantes do interior paulista na infância e/ou adolescência. Psicologia \& Sociedade, 25(1), 90-102. https://doi.org/10.1590/So102-71822013000100011

Tozdan, S., Briken, P., \& Dekker, A. (2019). Uncovering female child sexual offenders: Needs and challenges for practice and research. Journal of Clinical Medicine, 8(3), 401. https://doi.org/10.3390/jcm8030401

Watkins, B., \& Bentovim, A. The sexual abuse of male children and adolescents: A review of current research. The Journal of Child Psychology and Psychiatry, 33(1), 197-248. https://doi. org/10.1111/j.1469-7610.1992.tboo862.x 
Zimmermann, B. (2012). Mulheres que abusam sexualmente do gênero masculino: Um estudo exploratório (Trabalho de Conclusão de Curso em Psicologia). Universidade Presbiteriana Mackenzie, São Paulo, Brasil.

Zúquete, J., \& Noronha, C. V. (2012). Pedófilos e agressores sexuais de crianças e adolescentes: Narrativas a partir do cárcere. In M. T. A. D. Coelho \& M. J. Carvalho Filho (Orgs), Prisões numa abordagem interdisciplinar (pp. 145-160). Salvador: EdUFBa. https://doi. org/10.7476/9788523217358.010

Recebido em 15/11/2020 Aceito em 11/10/2021 